\title{
THE EFFECT OF NUMBER OF BLADES EXPERIMENTALLY ON THE HORIZONTAL WIND TURBINE SPEED
}

\author{
${ }^{*}$ Aiya N. Hussein ${ }^{1}$
}

\section{Basim A. Sadkhan ${ }^{1}$}

1) Mechanical Engineering Department, College of Engineering, Mustansiriyah University, Baghdad, Iraq

\begin{abstract}
The aim of this research is to find the effect of the number of blades on the wind turbine speed and to find which number of blades is suitable for low wind areas and high wind areas. In wind turbine design; the number of blades, tip speed ratio, and the rotational speed of the rotor are the most important factors. At first, the tip speed ratio and the number of blades must be selected. The power of a wind turbine generator depends on the rotational speed of the rotor. The increase in wind velocity leads to an increase in the rotor speed. At wind velocity $2.36 \mathrm{~m} / \mathrm{s}$, the rotational speed of 6 blades, 4 blades and 3 blades was 288,54 , and $34 \mathrm{rpm}$ respectively. And, at wind velocity $13.85 \mathrm{~m} / \mathrm{s}$, the rotational speed of 6 blades, 4 blades, and 3 blades are 1856, 2220, and $2103 \mathrm{rpm}$ respectively. So, when the number of blades decreases, the rotational speed will increase at high wind velocity. But, at low wind velocity, the rotational speed is more effective when the number of blades increases. So, 6 rotor blades were found as suitable for low wind velocity areas as in Iraq.
\end{abstract}

Keywords: Renewable Energy, Rotational Speed, Tip Speed Ratio, Number of Blades.

\section{Introduction}

The wind is a physical phenomenon of the atmosphere that occurs when the air masses move from areas of high pressure to low pressure. The atmosphere of high pressure is colder than that of low pressure. Because of such movement, heat energy converts into kinetic one. Generally, the topography has a serious impact on the weather. The wind is more found on the top of mountains than in valleys and in hills than high grounds. Wind velocities are reduced by snags like trees or buildings. The amount of wind may change from one year to the next, on a larger scale change over decades or more. [1]

The power was extracted from winds for more than hundreds of years known as windmills were used for pumping water or grinding corn. Historical designs are heavy, large, and inactive for producing energy. In the half of the twentieth century, because of the increase of global warming and environmental pollution, the world focus on renewable energy especially wind energy instead of fossil fuels. In 2018, wind energy gives solely around $20 \%$ of the global energy and around 30\% of the global energy needs will be given by wind energy in 2030 . Wind power can be harnessed by power devices called wind turbines for producing electricity. [2-4].

The wind turbines are large and tall structures. It has large blades and a rotor that is coupled with an electrical generator by using a gearbox to produce electrical power by converting the kinetic power of the wind to mechanical power as seen in fig. 1. The efficiency of a generator is depending on the rotational speed of the wind turbine. [5, 6]

*Corresponding Author: aiyaali18@yahoo.com 


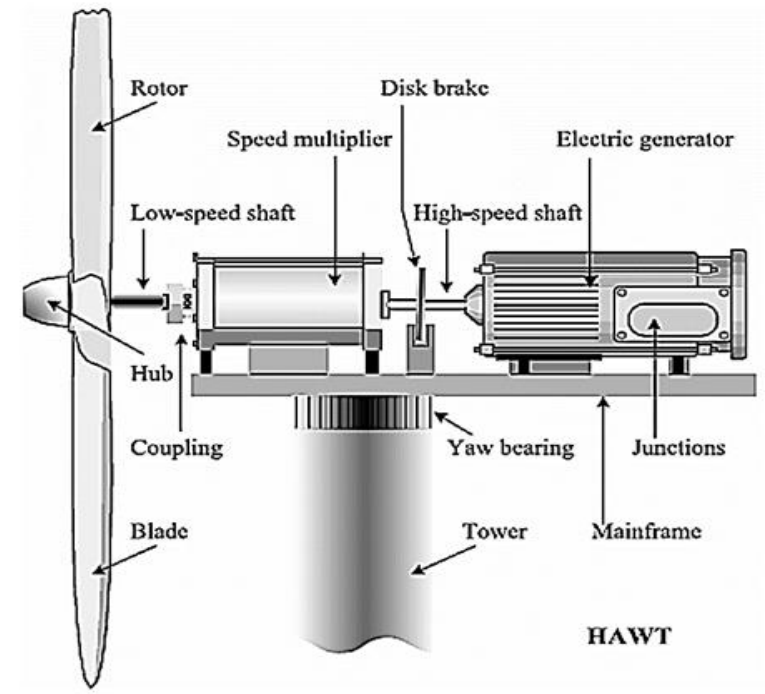

Figure 1. The wind turbine main component. [6]

The wind turbines are classified to many types, but, the most popular types are horizontal axis wind turbine (HAWT) and vertical axis wind turbine (VAWT). This classification were done according to the rotational shaft orientation. Fig. 2 shows the two main types of the wind turbines. The most used and common type of wind turbine is HAWT because it is more efficient and has low noise as compared with VAWT.

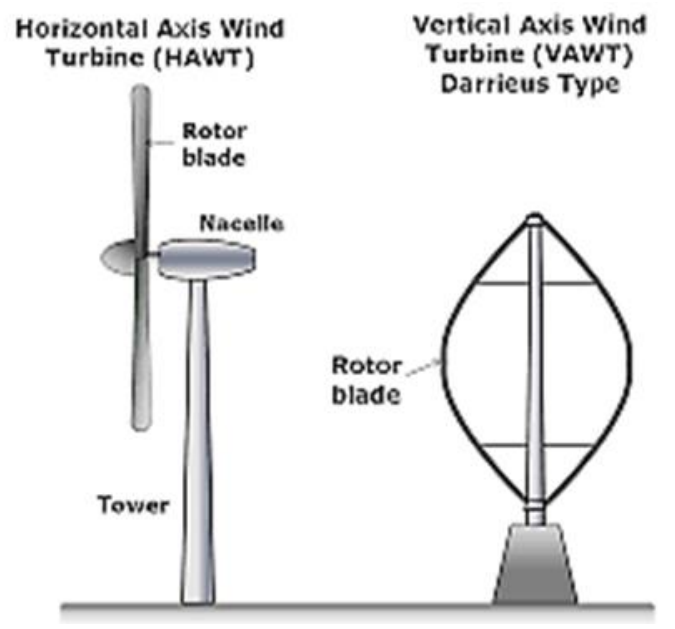

Figure 2. Types of wind turbine. [7]

The sources of renewable energy aren't spoiled if their energy being used. There have been many developments in the use the energy from wind for decades. So, the power effectiveness of the systems of wind energy possesses a high impression upon the economic analysis of such renewable energy type. More power can be generated when the wind turbine's effectiveness is raised, and there will be a decrease in the economic cost. Composite material has become the favorite material for wind turbine blades because of its low weight and density, high strength and stiffness, low cost, its resistance to weather conditions, and ease to manufacture the blades. [7, 8].

(Basim Ajel Sadkhan, 2009) [9] Studied the effect of 18 blades with a 1.5 tip speed ratio on the speed of the rotor and the power. It was found that the increase in wind velocity leads to an increase in the speed of the rotor and increases the power of the turbine.

(Hari Pal Dhariwal et al., 2012) [10] Studied the effect of TSR on the output RPM by designing a program named "Blade Calculator" by using VB.NET language for fast results. Blade number, tip speed ratio, wind speed, angle of attack, and blade efficiency were taken as inputs. The outputs were the power, RPM, coefficient of lift, and torque. The results show that increases in TSR led to increasing RPM linearly.

(P. O. Ochieng et al., 2014) [11] studied the effect of TSR on the coefficient of power. This study was done by using mathematical analysis to estimate the value of the TSR of a wind turbine. The coefficient of power $(\mathrm{Cp})$ was found at a specific TSR, which is considered an important parameter for the design of the turbine.

(R. Supreeth et al., 2019) [12] studied the efficiency of a rotor blade of a small-scale HAWT, analytically and experimentally. BEM was used to study the performance theoretically at the velocities of wind around ( $\mathrm{V}=1-20 \mathrm{~m} / \mathrm{s})$ and $(\mathrm{TSR}=1-20)$. Experimentally, the blade was scaled down to estimate the performance at the design conditions. The results showed that 
the experiment results are lower than the BEM results, if the hub losses, a three-dimensional flow, and the unstable aerodynamic influences are neglected.

(Andi F. Sudarma et al., 2020) [13] Studied the effect of the number of blades on the wind turbine performance. The blades were made from flat metal sheet. The number of blades was chosen as (3, 4, and 5) and built numerically by using ANSYS. The results show that an increase in the number of blades increases the torque and power of the wind turbine. The 5 number of the blade was tested experimentally in the wind tunnel at different wind speed $3.5 \mathrm{~m} / \mathrm{s}, 3.9 \mathrm{~m} / \mathrm{s}$, $4.3 \mathrm{~m} / \mathrm{s}, 4.6 \mathrm{~m} / \mathrm{s}$, and $5 \mathrm{~m} / \mathrm{s}$. It was found that numerical analysis produced more power than the experiment process.

The previous researchers studied about the effect of TSR and the number of blades on wind turbine blade design, power coefficient, and wind turbine performance. This research focus on the effect of the number of blades of $(6,4,3)$ on the wind turbine speed and found which one is suitable for low wind velocity areas.

\section{Methodology}

The design of wind turbine is based on several elements as Tip Speed Ratio (TSR), the number of blades, power factor, and profile used. Wind power can be extracted with a suitable blade design with the optimum tip speed ratio and increase rotor speed. In designing a wind turbine blade, at first; the TSR must be selected. The best TSR depends on the wind velocity and the wind turbine speed which depends on the number of blades and the profile used. TSR is defined as the relationship between rotational speed and wind velocity according to equation (1). [14, 15]

$\lambda=\frac{\omega \mathrm{R}}{\mathrm{V}_{\infty}}$

Where:

$$
\begin{aligned}
& \lambda=\text { tip speed ratio. } \\
& \omega=\text { wind turbine speed }(\mathrm{rad} / \mathrm{s}) \\
& \mathrm{V} \infty=\text { wind velocity }(\mathrm{m} / \mathrm{s}) \\
& \mathrm{R}=\text { rotor radius }(\mathrm{m})
\end{aligned}
$$

The definition of "fast turbines" refers to turbines with a high optimum TSR, while the term "slow turbines" refers to turbines with a low optimum TSR. So, the blades of a wind turbine have to be designed with the optimum TSRs for getting the ultimate power quantity from the wind. [16] The tip speed ratio was chosen as $(2,4$, and 5) with a number of blades of $(6,4$, and 3$)$ respectively according to the Table 1 .

Table 1. The Relation Between TSR With The

\begin{tabular}{cc}
\multicolumn{2}{c}{ Number of Blades. [17] } \\
\hline TSR & Number of Blades \\
\hline 1 & $12-36$ \\
1.5 & $6-18$ \\
2 & $4-12$ \\
3 & $3-6$ \\
4 & $2-4$ \\
$5-8$ & $2-3$ \\
$8-15$ & $1-2$ \\
\hline
\end{tabular}

A full-scale wind turbine blade is expensive and required large space and complex manufacturing processes; So, a prototype of the blade was used. The blade geometry is described in fig. 3 to get maximum benefits of the winds with a curvature thickness to chord ratio (f/c) of (0.1). The blade chord is calculated according to equation (2). The radius of the blade ( $\mathbf{R}_{\mathbf{a}}$ ) was calculated according to equation (3) and fig. 4. [17]

$$
\begin{aligned}
& r=0.7 R_{a} \\
& R_{a}^{2}=\left(R_{a}-f\right)^{2}+\frac{1}{4} C^{2}
\end{aligned}
$$




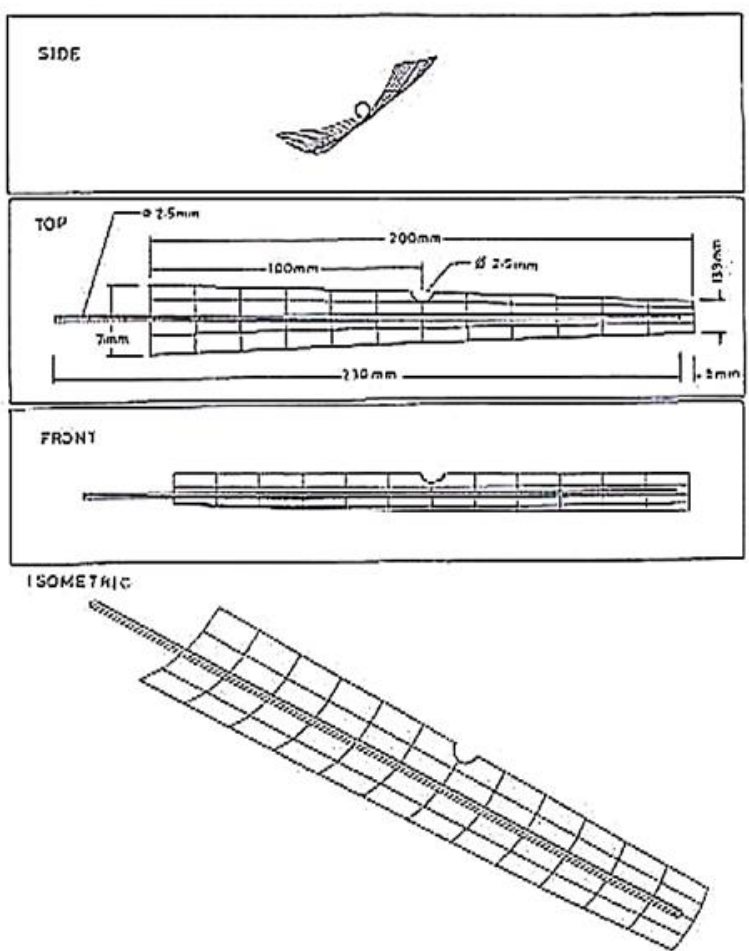

Figure 3. The Profile of the Blade.

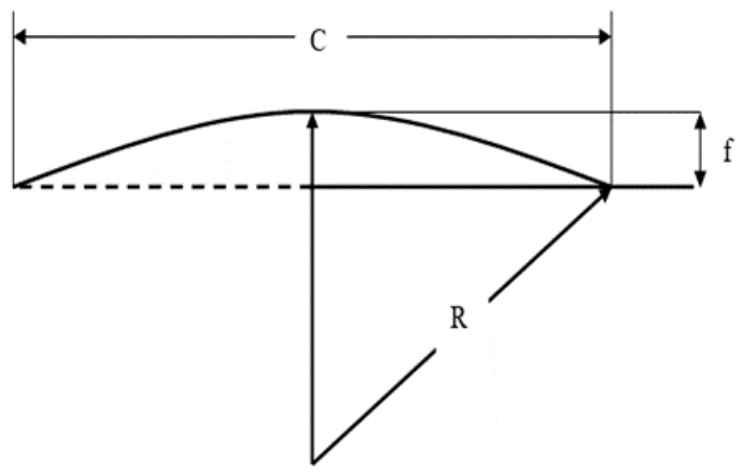

Figure 4. The Radius of the Blade.

The blades were made from fiberglass and polyester as a matrix. Fig. 5 shows the three types of rotors.

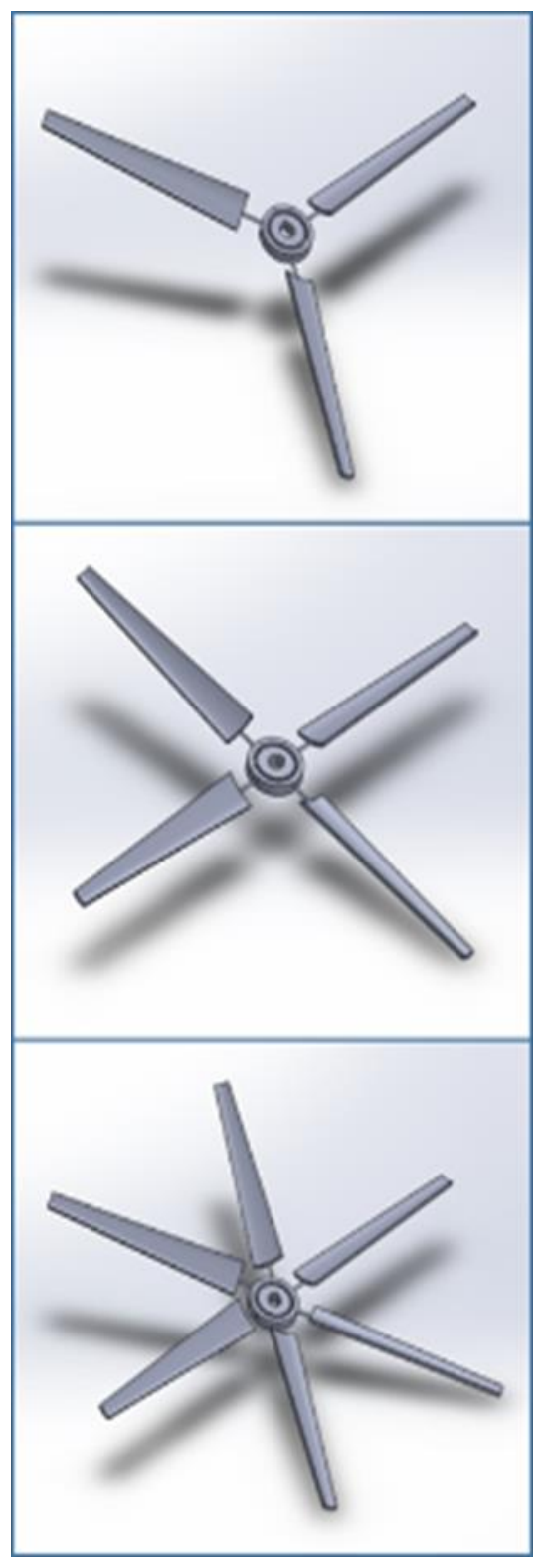

Figure 5. Rotor Model

\section{The Test Rig}

A full-size model testing is expensive and required a large foundation for the modified model. The experiment test rig was used to measure wind turbine speed according to different wind velocities. It contains few components as listed below and shown in fig. 6:

1. Inverter (regulator or speed controller) type LS-M100 (2hp, 200-240 v, 1Ф, 1$50 \mathrm{~Hz}$ ). 
2. Air Generator type GAMAK (2800rpm, $1.1 \mathrm{KW}, 220 \mathrm{~V}, 50 \mathrm{~Hz}$ ) with four blades at $40^{\circ}$.

3. Duct.

4. Wind Turbine made of blades, hub, bearings, and shaft.

5. Anemometer type (MT-4615).

6. Oil.

7. Tachometer type (DT-2234C+).

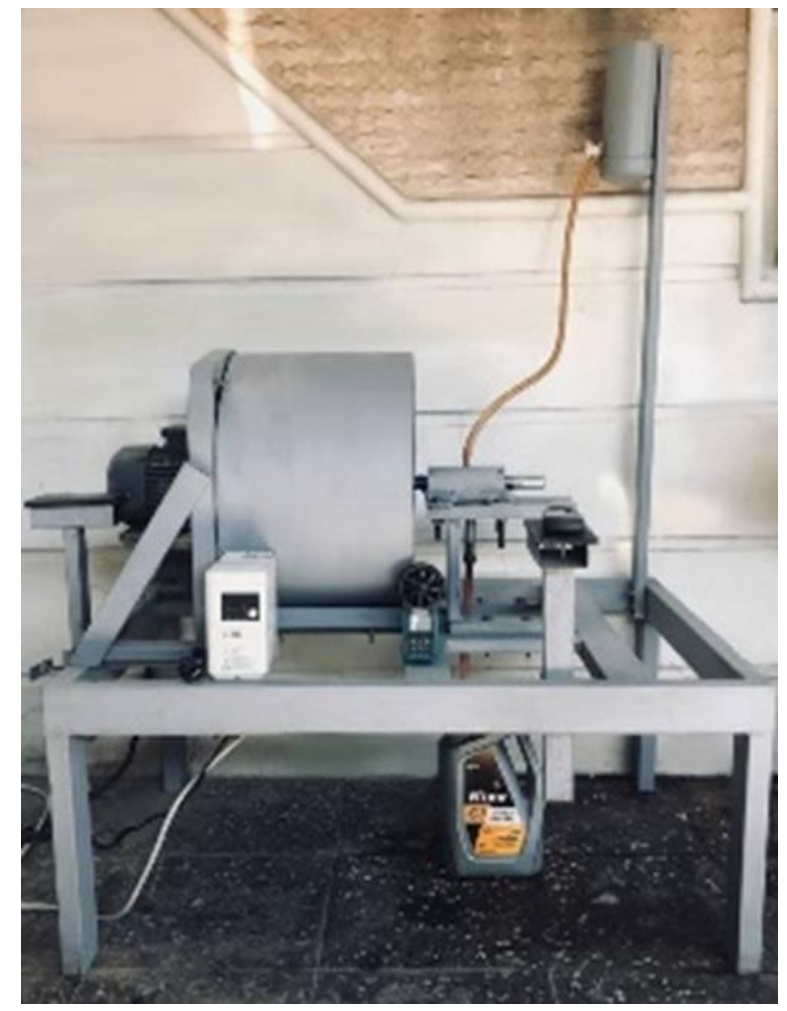

Figure 6. Test Rig Components.

The test rig design has the following advantages:

- The change in air velocity leads to a rapid change in rotor Wind Turbine speed.

- Visual observation of the cracks which happened in the wind turbine blade.

- Easy to measure the wind velocity and the rotor speed.

- Low cost as compared with full-scale wind turbine planet.

And the following disadvantages were noticed in the designing of the test rig:
- Limitation in wind turbine rotor diameter.

- Noise notification.

The wind velocity was measured by using the anemometer and the rotational speed of the wind turbine was measured by the tachometer.

\section{Results}

The wind turbine must be designed with maximum output power. This can be found by the rotational speed of the rotor, which is connected with a generator by a shaft. Fig. 7 (a, b, c) shows the relationship between the wind velocity and the rotor speed for 6, 4, 3 blades. As found, when the wind velocity increases the rotational speed of the wind turbine increase also.

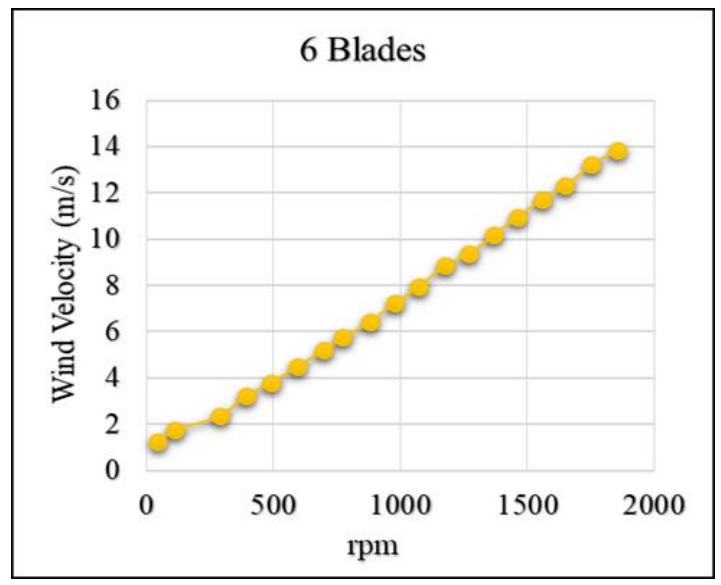

(a)

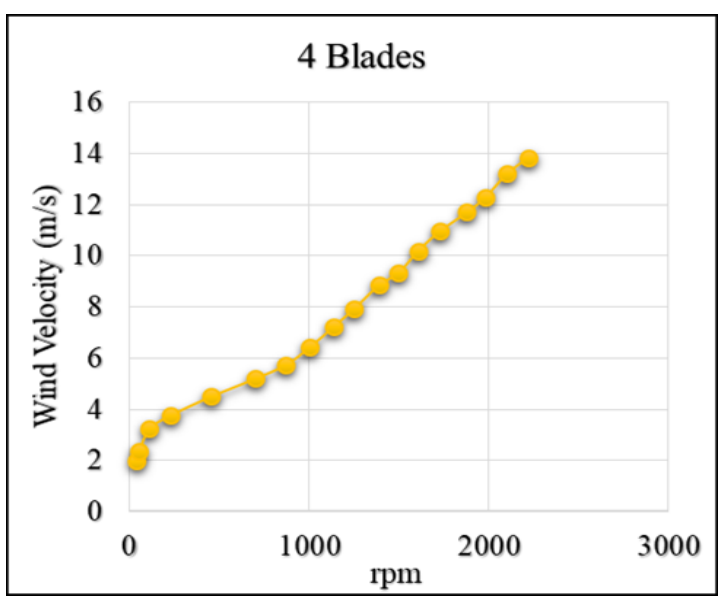

(b) 


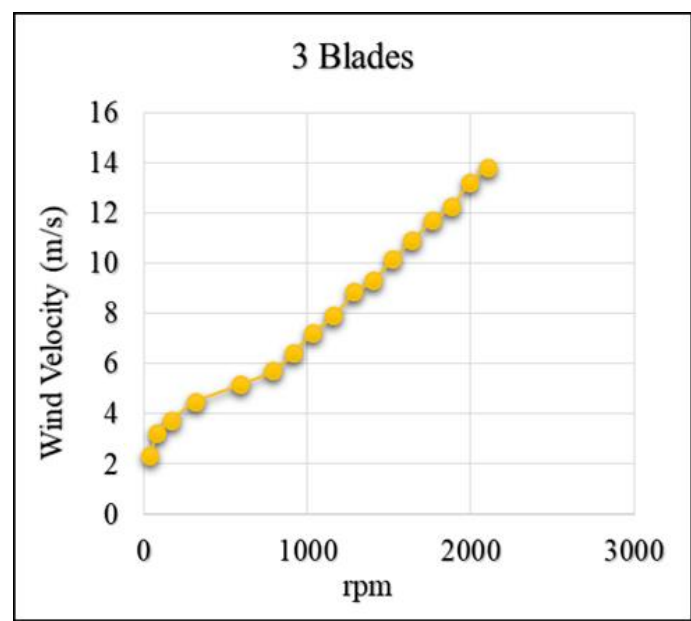

(c)

Figure 7. The Relationship Between Wind Velocity and rpm for ((a) 6 blades. (b) 4 blades. (c) 3 blades).

As noticed in fig. 8, 4 blades have a high rotational speed at a high wind velocity (more than $6(\mathrm{~m} / \mathrm{s}))$ as compared with 6 blades and 3 blades. 6 blades rotate at a low wind velocity (less than $6(\mathrm{~m} / \mathrm{s})$ ); so, it is suitable for low wind areas, but it is not effective at high speed and it has the lowest rotational speed. Fig. 9 and Table (2) show a comparison between the three TSRs and the number of blades with wind velocity and wind turbine speed. In high wind velocity, the increase in the number of blades will make the wind turbine act as solid wall and the wind will gets over it instead passing through it with low extraction from the wind and vice versa in low wind velocity. So, 6 blades were found as a suitable choice for low wind velocity areas. The results are agreed well with references [9], [10], and [13].

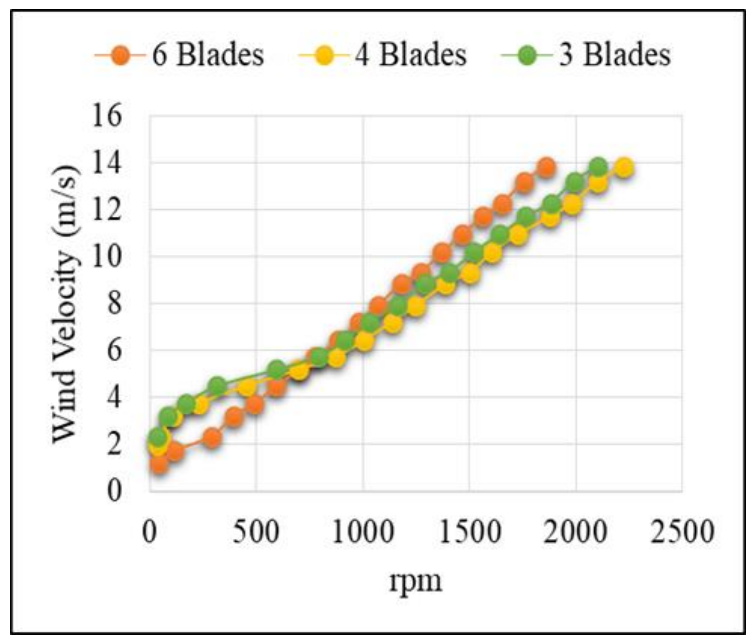

Figure 8. A comparison between 6, 4, 3 blades.

Table 2. a comparison between the number of blades.

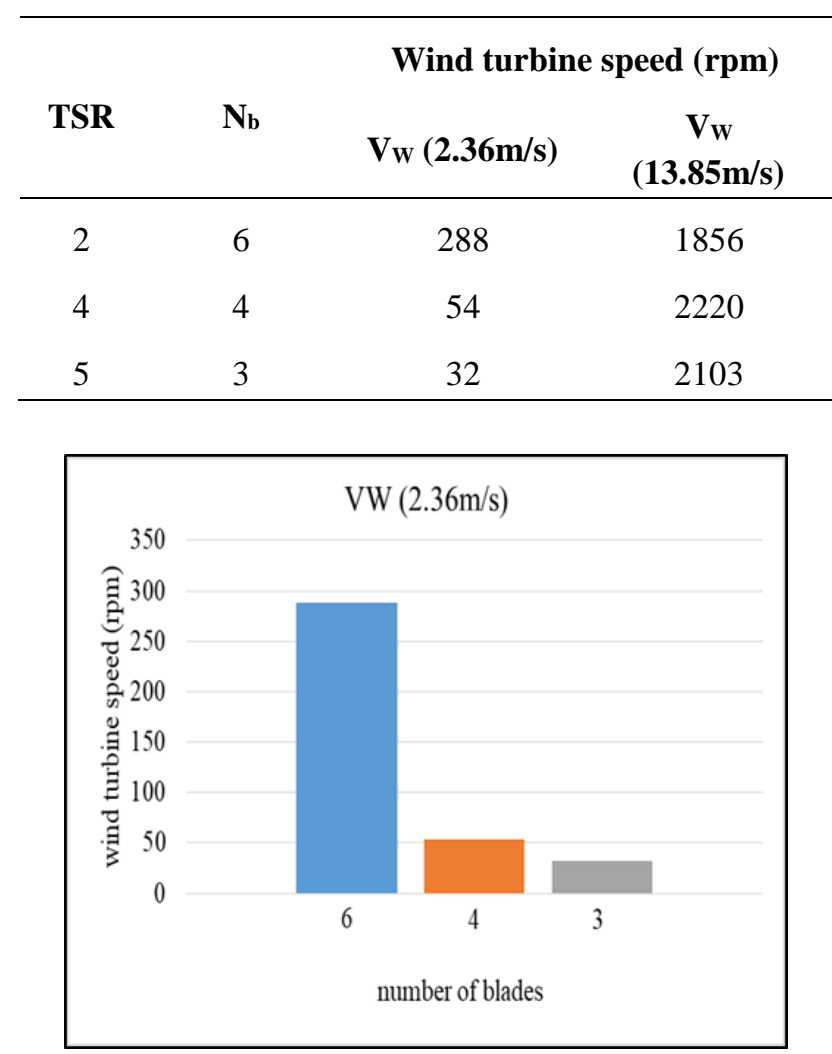

(a) 


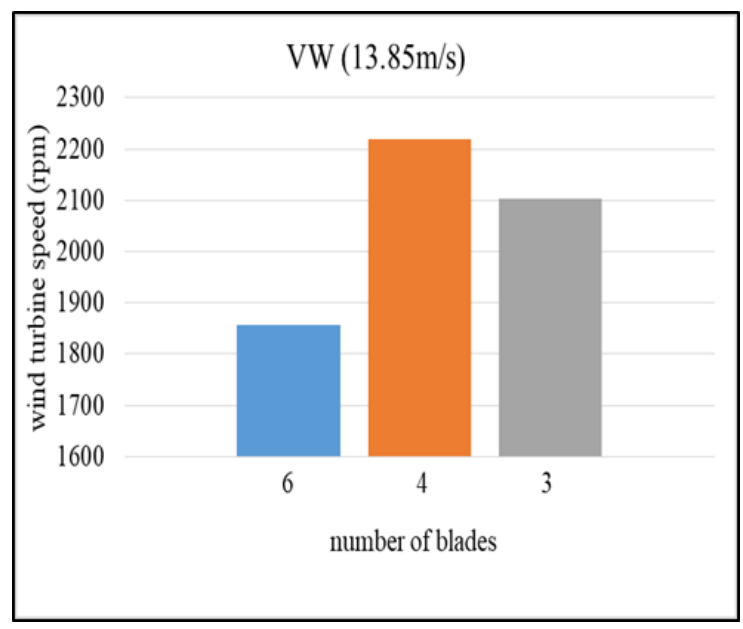

(b)

Figure 9. COMPARISON with (a) low wind velocity. (b) high wind velocity.

\section{Conclusions}

The wind turbine generator efficiency depends on the rotational speed of the wind turbine. The wind turbine must design with an optimum tip speed ratio and a suitable number of blades. It was concluded:

- The increase in wind velocity will increase the wind turbine rotational speed.

- The increase in tip speed ratio will increase the wind turbine rotational speed at high wind velocity.

- 4, and 3 blades wind turbine has a high rotational speed as compared with the 6 blades wind turbine.

- 6 blades are more effective at low wind velocity as compared with 3 , and 4 blades.

- A more number of wind turbine blades are suitable for low wind velocity areas. But a fewer number of blades has a high rotational speed at high wind velocity.

\section{Acknowledgment}

The authors would like to thank AlMustansiriyah University, College of Engineering / Mechanical Engineering Department for academic guidance and support.

\section{Conflict of Interest}

The authors confirm that the publication of this article causes no conflict of interest.

\section{Abbreviations}

$\begin{array}{ll}\text { TSR } & \text { Tip Speed Ratio } \\ \mathrm{N}_{\mathrm{b}} & \text { Number Of Blades } \\ \mathrm{V}_{\mathrm{w}} & \text { Wind Velocity } \\ \Lambda & \text { Tip Speed Ratio } \\ \Omega & \text { Wind Turbine Speed } \\ \mathrm{R} & \text { Rotor Radius } \\ \mathrm{R}_{\mathrm{a}} & \text { Radius Of The Blade } \\ \mathrm{F} & \text { Curvature Thickness } \\ \mathrm{C} & \text { Chord }\end{array}$

Rpm Revolution Per Minute

HAWT Horizontal Axis Wind Turbine

VAWT Vertical Axis Wind Turbine

\section{References}

1. Tony Burton, David Sharpe, Nick Jenkins, and Ervin Bossanyi (2001) "Wind Energy Handbook" John Wiley \& Sons, Ltd Baffins Lane, Chichester West Sussex, Po19 1ud, England.

2. R. Ataa, and Y. Kocyigit (2010) "An adaptive neuro-fuzzy inference system approach for prediction of tip speed ratio in wind turbines" Expert Systems with Applications 37, pp. 5454-5460.

3. R. Supreeth, A. Arokkiaswamy, Nagarjun J. Raikar, H. P. Prajwal (2019) "Experimental Investigation of Performance of a Small Scale Horizontal Axis Wind Turbine Rotor Blade" International Journal Of Renewable Energy Research, Vol.9, No.4.

4. Peter J. Schubel and Richard J. Crossley (2012) "Wind Turbine Blade Design" Energies, 5, pp. 3425-3449.

5. Parth Rathod, and Hiren Shah (2016) "Simulation and Parameter Evaluation of 
Wind Turbine Blade", IJMER, Vol. 6, Iss. 3, pp. 35-43.

6. Asress Mulugeta Biadgo and Gerawork Aynekulu (2017) "Aerodynamic Design of Horizontal Axis Wind Turbine Blades", FME Transactions 45, pp. 647-640.

7. Gizachew Dereje, and Belete Sirahbizu (2019) "Design and Analysis of $2 M W$ Horizontal Axis Wind Turbine Blade" IJISET - International Journal of Innovative Science, Engineering \& Technology, Vol. 6 Issue 5.

8. Herbert J. Sutherland (2000) "A Summary of the Fatigue Properties of Wind Turbine Materials" Sandia National Laboratories\ Wind Energy Technology Department, USA, Wind Energy, 3, 1-34.

9. Basim Ajel Sadkhan (2009) "Fatigue Life Of Windmill Turbine Blade Manufactured From Fibreglass Caused By Aerodynamic Forces", Ph.D. Thesis, University Of Technology.

10. Hari Pal Dhariwal, Dharampal Yadav and Barun Kumar Roy (2012) "Prediction The Effect Of Tip Speed Ratio On Wind Turbine Generator Output Parameter", vol. 1, no. 3, pp. 125-130.

11. P. O. Ochieng, A. W. Manyonge, And A. O. Oduor (2014) "Mathematical Analysis Of Tip Speed Ratio Of A Wind Turbine And Its Effects On Power Coefficient" International Journal Of Mathematics And Soft Computing, Vol.4, No.1, 61-66.

12. R. Supreeth, A. Arokkiaswamy, Nagarjun J. Raikar, and H. P. Prajwa (2019) "Experimental Investigation of Performance of A Small Scale Horizontal Axis Wind Turbine Rotor Blade" International Journal of Renewable Energy Research, Vol.9, No.4.

13. Andi F. Sudarma, Muhammad Kholil, Subekti Subekti, and Indra Almahdy (2020) "The Effect of Blade Number on Small Horizontal Axis Wind Turbine (HAWT) Performance: An Experimental and
Numerical Study" International Journal of Environmental Science and Development, Vol. 11, No. 12, pp. 555-560.

14. N.S. Çetin, M.A. Yurdusev, R. Ata and A. Özdemir (2005) "Assessment Of Optimum Tip Speed Ratio Of Wind Turbines", Mathematical and Computational Applications, Vol. 10, No. 1, pp. 147-154, 2005.

15. Mehmet Bakirci, and Sezayi Yilmaz (2018) "Theoretical And Computational Investigations of The Optimal Tip Speed Ratio Of Horizontal-Axis Wind Turbines" Engineering Science And Technology, An International Journal, Volume 21, Issue 6, 1128-1142.

16. Technical Application Papers No.13 "Wind Power Plants" ABB group, ABB SACE A division of ABB S.p.A., Bergamo - Italy, 2011.

17. Ikhlase Mohammed Al-Fayad (1997) "Comprehensive Evaluation and Aerodynamic study of wind energy conversion system for Iraq", Ph.D. thesis, University of Technology. 